[This is the pre-publication version of Henry, A. (in press). Enablements and constraints: Inventorying affordances associated with lingua franca English. International Journal of Bilingual Education and Bilingualism. DOI:10.1080/13670050.2015.1014465]

\title{
Enablements and constraints: Inventorying affordances associated with lingua franca English
}

\author{
Alastair Henry \\ Department of Social and Behavioural Studies, University West, Trollhättan, \\ Sweden \\ al.henry@hv.se
}

\begin{abstract}
Transcultural flows of capital, culture and communication have created conditions for the widespread movement of people around the globe, leading to increasing diversity in countries of destination (Blommaert 2010). In contexts of global migration lingua franca English is indispensable in initial and survival communication (Clyne and Sharifian 2008). For migrants to northern European countries where lingua franca English functions as a 'contact language' in 'contact zone encounters' (Canagarajah 2013), it is of value not only as a communication medium, but also as a resource for learning typologically similar host-country languages. Drawing on the concept of affordances (Singleton and Aronin 2007; van Lier 2000), the purpose of this study is to create an inventory of the ways in which English can facilitate, but also constrain social interaction and the acquisition of Swedish. Interviews conducted with 14 recently-arrived migrants with English in their repertoires revealed the presence of enabling and constraining affordances in social, classroom, material and cognitive domains.

Discussing the study findings, it is suggested that the ways in which the individual attunes to an affordance associated with English, perceiving it as either enabling or constraining, is dependent on their current motivational and affective state and in-the-moment cognitive processing.
\end{abstract}


Key words: affordances; ELF; global English; migration; Sweden; language mode theory; individual differences

\section{Introduction}

Transcultural flows of capital, culture and communication have created conditions for the widespread movement of people around the globe, leading to increasing diversity in countries of destination. As a consequence of escape from conflict and oppression, spousal migration, family reunification and economic mobility, migrants today settle in host countries often far removed from spaces and cultures of origin (Blommaert 2010). In global migrations there can be little doubt about the role and importance of English. As Clyne and Sharifian (2008) note, lingua franca English “is currently indispensable, and will continue to be such in the foreseeable future, for both initial and survival communication across many nations and cultures” (p. 28.10). For migrants to northern European countries where English has become embedded in local cultures (McKay 2002; see also Henry and Goddard in press), not only is lingua franca English of value as a communication medium, but also as a resource for learning host country languages. Drawing on the concept of affordances (Singleton and Aronin 2007; van Lier 2000), the purpose of this study is (i) to identify enabling and constraining phenomena associated with English in social interaction and the acquisition of Swedish and (ii) drawing on this inventory, to consider the implications for migrants' language learning.

The paper begins with a short summary of the presence and nature of English in the Swedish societal context and, for English-speaking migrants, its facilitative potential both in communicating with speakers of Swedish, and as a steppingstone to learning Swedish. Thereafter follows a review of the literature on affordances that includes a discussion of the ways in which, functionally, the concept encompasses not only facilitative properties but also those that impose constraints. Following an outline of the methods employed, in the Results 
section affordances associated with English are presented in four domains; a social domain, a classroom domain, a material domain and a cognitive domain. The implications for communication and the acquisition of Swedish are discussed with focus directed to the ways in which a similar affordance can be differently perceived as either enabling or constraining. Finally, the value of an inventorying approach is assessed and the implications of the findings for practitioners is considered.

\section{Literature Review}

\section{English in Sweden}

Sweden is one of the main EU countries of destination for asylum seekers, on a per capita basis accepting the largest number of asylum-seeking migrants in the Union (OECD 2013). The environment awaiting migrants is one where “an overwhelming Anglicization” has taken place and where English can "be considered as a second language in the Swedish daily living environment” (Cabau 2009, 134). English has long been a prominent feature in media offerings, some commentators suggesting that given "the current output of American and British TV series and documentaries, the state and commercial TV stations are practically running a continuous course in spoken English” (Hultgren, Gregersen and Thogersen 2014, 17). English is widely encountered in online environments (Swedish Media Council 2013) and access to high-speed Internet is universal, Sweden ranking first of 142 countries in the World Economic Forum’s ‘Networked Readiness Index’ (World Economic Forum 2012). Levels of proficiency are high, Sweden often coming at the top of international surveys of language competence (e.g. the European Commission’s Survey on Language Competences, SurveyLang, (European Commission 2012a) and EF’s worldwide English Proficiency Index (EPI)). Attitudes to English are overwhelmingly positive (European Commission 2012b) and English is regarded as valuable in facilitating interactions with migrants whose Swedish is not sufficient to allow for successful communication (Bolton and Meirkord 2013). 
In its facilitation of everyday interactions, English has a lingua franca function in the sense that it is used as an L2 in a larger community of the language's speakers (Cook 2009, 2013). However, in contrast to a situation where "the crucial contact is with the central language of the community and its native speakers” (Cook 2013, 35) (emphasis added), here the larger community is comprised of non-native speakers of English. In these circumstances English, in the Swedish setting, is best conceptualised as a "contact language” used in "contact zone encounters” (Canagarajah 2013, 68). It is a language that, in Canagarajah’s framing, functions as part of a translingual repertoire in which local languages are included and where, in communicative practices, English and local languages are combined in social interaction. For migrants to Sweden, English and Swedish both provide communicative opportunities, the mixing of which will differ depending on the nature of the communicative situation and, as Canagarajah (2013) explains, “from speaker to speaker according to their level of proficiency in English and according to their language backgrounds” (68). This means that speakers of different L1s - say Swedish and Arabic - may speak to each other in a form of English that is mixed with and marked by the influence of their other languages. In this sense the use of English as a lingua franca can be conceived of as a form of social action or, in Cook's (2013) terms, a manifestation of multi-competence in action.

In addition to its potential in facilitating everyday communication, competence in English is also likely to be advantageous to migrants in learning Swedish. For many, Swedish will be typologically more similar to English than their L1. In a range of studies positive effects of bi/multilingualism have been found in L3 learning (see e.g. Cenoz 2003; Jessner 2008) and crosslinguistic influence (CLI) has been identified in most aspects of language acquisition (DeAngelis and Dewaele 2011). CLI, and the benefits associated with it, is recognised as stronger in languages perceived to be similar to one another, its effects arguably decreasing for languages learners perceive to be distant (Ringbom 1986; Singleton 2006). Consequently, 
for speakers of Afroasiatic languages such as Arabic or Somali (languages spoken by the members of the currently largest asylum-seeking groups in Sweden), but also languages within e.g. the Slavonic or Romance typological groups, English is likely to function as an important resource in the learning and acquisition of Swedish (cf. Ringbom 1987).

\section{Affordances}

Although Gibson's (1979) theory of affordances was first brought to the attention of SLA researchers over a decade ago (Segalowitz 2001; van Lier 2000), it is only in recent years that, in the context of multilingual acquisition, the concept has been systematically investigated (Aronin 2014; Aronin and Singleton 2010, 2012; Singleton and Aronin 2007) and operationalised in empirical research (e.g. Dewaele 2010; Otwinowska-Kasztelanic 2009, 2011). Even though studies drawing on theories of affordances remain few, Aronin and Singleton (2012) argue that an affordances lens offers important potential for identifying multilinguals’ language learning possibilities.

The concept of affordances was developed to explain the interrelatedness and interplay between organisms and environments. As Gibson (1979) explains, an environment’s affordances are "what it offers the animal, what it provides or furnishes, either for good or ill" (127) and includes possibilities that are both positive and negative in nature. Although for Gibson, affordances are naturally existing relationships, actionable between the individual and the environment, subsequent scholars (Greeno 1998; Norman 1999) emphasise that an affordance necessarily requires the individual's awareness of the potential offered. Norman (1999) emphasises the important distinction between objective affordances (that is to say the physical properties in an environment) and perceived affordances (ways in which such are recognized, understood and perceived). Further, affordances are not 'related to' in a 
decontextualised, objective way, but in manners relative to the individual and concordant with each individual's unique attributes, abilities and capacities. An affordance becomes such as a consequence of the individual's capacity to recognize and react to a feature of the environment, the individual's behaviour thus conceived as an "attunement" to the affordance (Greeno 1998, 8).

The acquisition of a second language, Segalowitz (2001) argues, “involves attuning one’s attention system to perceive the communicative affordances provided by the linguistic environment” (15). As van Lier (2000) makes clear, as a consequence of variations in the ways in which it is perceived, an objective affordance can be differently acted upon and differently utilized by different individuals. This he masterfully explains using the example of a forest leaf:

In the forest a leaf can offer very different affordances to different organisms. It can offer crawling on for a tree frog, cutting for an ant, food for a caterpillar, shade for a spider, medicine for a shaman, and so on. In all cases the leaf is the same: its properties do not change; it is just that different properties are perceived and acted on by different organisms. (252)

Further, van Lier (2000) points out that, although the term 'affordance' connotes something positive, affordances can hinder as well as facilitate learning. Citing Shotter and Newson (1982, 34), he makes clear that "the linguistic world to which the learner has access, and in which she becomes actively engaged, is 'full of demands and requirements, opportunities and limitations, rejections and invitations, enablements and constraints - in short affordances"” (van Lier 2000, 253) (emphasis added). The sense that, because of individuals’ varying perceptions in ever-shifting contexts, an affordance can have both enabling and constraining properties is something that has been largely overlooked in the work currently being conducted in the multilingual field which, so far, has emphasised only its facilitative 
properties (e.g. Aronin 2014; Aronin and Singleton 2010, 2012; Dewaele 2010; OtwinowskaKasztelanic 2009, 2011; Singleton and Aronin 2007). For example Dewaele (2010) found that, at intermediate levels of proficiency, knowledge of typologically related languages can function as an affordance in facilitating communication in challenging situations, while Otwinowska-Kasztelanic $(2009,2011)$ found that while multilingual learners are aware of the facilitating affordances provided by cross-linguistic similarities, the ways in which these benefits are taken advantage of “depends on the language learner’s capacity to perceive and utilize the linguistic affordances embedded in the studying environment” $(2011,13)$.

However in fields where the concept is more established and has a central role in conceptualisations of human-environment interrelationships (in particular the sociology of technology), affordances are recognised as being both enabling and constraining, positive and negative. For example, Akrich and Latour (1992, 259) define affordances as "what a device allows or forbids from the actors - humans and nonhuman - that it anticipates; it is the morality of a setting both negative (what it prescribes) and positive (what it permits)”, while Hutchby (2001, 448) emphasizes that, functionally, affordances constitute “enabling, as well as constraining, factors in a given organism’s attempt to engage in some activity”.

\section{Purpose}

Aronin (2014) argues that there is expediency in “inventorying affordances” in a "detailed way”, “in specific sociolinguistic environments” and "for particular languages” (164). Given (i) the typological similarities between Swedish and English, and (ii) the ubiquity of English in Swedish society, its embeddedness in local cultures, and Swedish-speakers' competence in English, migrants to Sweden with English in their repertoires are likely to perceive a range of affordances associated with English. These affordances can be discerned both in social interaction and in learning Swedish. Some of these may be enabling (i.e. supporting 
interaction and learning). Others may be constraining (i.e. creating obstacles to interaction and learning). The purpose of this study is twofold; first to identify migrants' perceptions of enabling and constraining phenomena associated with English in social interaction and the learning and acquisition of Swedish and, secondly, using this inventory to consider the implications such affordances have for TL acquisition.

\section{Method}

\section{Participants}

Dewaele (2010) contends that the concept of affordances is of particular value when considering the situation of individuals in particular stages of language learning. Specifically, its potential to illuminate facilitative aspects of multilingual learning may diminish for learners with either very high or very low communicative competence. A linguistic affordance, he argues, is analogous to a crutch, offering scant assistance for those with no legs or two healthy legs, but of potentially great value for those with only one functioning leg. With this in mind, participation was restricted to migrants who, although in the early stages of learning Swedish, had nevertheless acquired basic communicative skills.

Fourteen migrants with English in their repertoires participated in the study. They were enrolled on two consecutive university-provided programs offered to migrants with post upper-secondary education and CEFR B1-level skills in Swedish. The purpose of the education was to provide a fast-track into work or higher education. In addition to courses in the Swedish language, social studies courses and periods of practice were included in the programs. At the beginning of each program, the total number of enrolled students completed a questionnaire seeking information on their country of origin, reasons for coming to Sweden, language repertoires, self-assessed competence in each language, education, work history and 
time in Sweden. Inclusion criteria were: i) being in Sweden for less than two years, ii) selfassessed communicative competence in English ${ }^{\mathrm{i}}$, and iii) not being a speaker of English from birth.

The participants (identified by pseudonyms), their age at the time of the interviews, gender, country of origin, language repertoire and migrant status (employing Vertovec’s (2007) taxonomy) are set out in Table 1. The participants’ professional experience included engineering, chemistry, IT, medicine, medical science, law, finance and administration, TV production, translation and education.

Table One. Study participants.

\begin{tabular}{|c|c|c|c|c|}
\hline Name & Sex & Age & Country of origin and language repertoire & Migrant status \\
\hline Andras & M & 37 & Hungary / Hungarian; English & spouse $^{* *}$ \\
\hline Babak & $\mathrm{M}$ & 32 & Palestine / Arabic; French; English & asylum-seeker \\
\hline Carmen & $\mathrm{F}$ & 58 & Philippines / Tagalog; Wary-Wary; English; Spanish & spouse* \\
\hline Daria & $\mathrm{F}$ & 29 & Syria / Arabic; French; English & asylum-seeker \\
\hline Elena & $\mathrm{F}$ & 25 & Belarus / Russian; German; English & spouse* \\
\hline Firman & $\mathrm{M}$ & 29 & Iraq / Kurdish; Arabic; English & spouse $^{* *}$ \\
\hline Galina & $\mathrm{F}$ & 48 & Ukraine / Russian; Ukraine; English & spouse* \\
\hline Hanna & $\mathrm{F}$ & 35 & Poland / Polish; Russian; German; English & spouse $^{* * *}$ \\
\hline Jasna & $\mathrm{F}$ & 51 & Serbia / Serbian; English & spouse $^{* *}$ \\
\hline Laura & $\mathrm{F}$ & 59 & Philippines / Tagalog; English & spouse* \\
\hline Mumtaz & $\mathrm{F}$ & 35 & Pakistan / Urdu; English & spouse*** \\
\hline Najwa & $\mathrm{F}$ & 23 & Jordan / Arabic; French; English & spouse $^{* *}$ \\
\hline Safia & $\mathrm{F}$ & 33 & Syria / Arabic; French; English & asylum-seeker \\
\hline Visam & $\mathrm{M}$ & 31 & Lebanon / Arabic; French; English & spouse $^{* *}$ \\
\hline
\end{tabular}

Note:

* spouse of Swedish citizen

** spouse of Swedish citizen with migrant background

$* * *$ spouse of migrant worker

\section{Interviews}

During the winter/spring of 2013 two semi-structured interviews were carried out with each participant. ${ }^{\text {ii }}$ The longest interview lasted 56 minutes, the shortest 28 minutes. Interviews were structured around the following questions:

- What are the biggest challenges you face learning Swedish? 
- What opportunities do you have to speak Swedish outside school?

- Do you find your knowledge of other languages helpful when learning Swedish?

- Do you find your knowledge of other languages helpful when communicating with Swedish people?

Follow-up questions in this study focused on participants' perceptions of the ways in which, in different situations, English could be experienced as a resource and the nature of perceived advantages and disadvantages involved in speaking and using English. The interviews were carried out by the author, a speaker of both English and Swedish in the language (Swedish or English) chosen by the interviewee. Six of the participants chose to be interviewed in Swedish and six in English. One participant switched constantly between English and Swedish in both interviews, while another chose to have the first interview conducted in English and the second in Swedish. The interviews were audio-recorded and verbatim transcripts were made, resulting in a corpus of 76500 words.

\section{Method of analysis}

Concordant with the purpose of providing an inventory of perceived affordances, a thematic analytical approach was used. Thematic analysis involves searching a data set with the aim of discovering repeated patterns of meaning which are then interpreted. The analytical process was carried out in accordance with procedures described by Braun and Clarke (2006). Following initial familiarization with the transcripts ${ }^{\mathrm{iii}}$ they were then entered into NVivo 10.0 and read through again, interesting features coded in NVivo as nodes. From these initial nodes a smaller number of themes was generated, data extracts assigned to them. A process of further review took place before a final set of themes was generated, these themes then clustered together into four categories representing different 'domains' (see below). In the 
presentation of transcript extracts * indicates that the section comes from an interview carried out in Swedish and is thus a translation. Bold face indicates a language switch.

\section{Results}

Affordances associated with English are grouped together by domain, an "environment which provides a substantial number of affordances favouring a specific language or specific languages (as opposed to another or other languages) in a multilingual society” (Aronin and Singleton 2012, 321). Affordances can be found in cognitive domains (i.e. associated with language processing and processes of learning), as well as societal domains (Singleton and Aronin 2007). In the analysis of the data affordances identified by the participants were found in four domains; a social domain (affordances in everyday interactions), a material domain (affordances in digital medias), a classroom domain (affordances associated with formal learning environments) and a cognitive domain (affordances associated with language processing and processes of learning). An overview of these affordances associated is provided in Table 2.

Table 2. An inventory of affordances associated with English

\begin{tabular}{|l|l|}
\hline Domain & Types of affordance \\
\hline $\begin{array}{l}\text { Social } \\
\text { (affordances in } \\
\text { everyday interactions) }\end{array}$ & $\begin{array}{l}\text { Enabling } \\
\text { English functions as a communicative medium facilitating social } \\
\text { interaction and transactions } \\
\text { Navigating in an unfamiliar culture becomes more manageable } \\
\text { Code-switches to English enable communication to be } \\
\text { maintained when problems are encountered in Swedish } \\
\text { Communicating in English is less resource-intensive } \\
\text { (cognitive/affective) } \\
\text { Constraining }\end{array}$ \\
\hline
\end{tabular}




\begin{tabular}{|c|c|}
\hline & $\begin{array}{l}\text { Reliance on English can extend the period before using Swedish } \\
\text { with TL-speakers becomes the normal mode of interaction } \\
\text { High demands on cognitive/affective resources when active } \\
\text { choices to use Swedish are made }\end{array}$ \\
\hline $\begin{array}{l}\text { Material } \\
\text { (affordances in digital } \\
\text { medias) }\end{array}$ & $\begin{array}{l}\text { Enabling } \\
\text { Swedish subtitles for English language TV programs and films } \\
\text { facilitate the acquisition of Swedish } \\
\text { English-language digital resources (dictionaries, translation } \\
\text { tools) facilitate the acquisition of Swedish } \\
\text { Constraining } \\
\text { A predominance of English language media and resources (TV } \\
\text { programs, films, digital media, translation tools) limits exposure } \\
\text { to Swedish and makes it easier to rely on English }\end{array}$ \\
\hline $\begin{array}{l}\text { Classroom } \\
\text { (affordances associated } \\
\text { with formal learning } \\
\text { environments) }\end{array}$ & $\begin{array}{l}\text { Enabling } \\
\text { English provides a channel for metacommunication } \\
\text { English provides a functional lingua franca in social interaction } \\
\text { Constraining } \\
\text { Reliance on English for metacommunication can delay the use of } \\
\text { Swedish } \\
\text { Use of English in social interaction limits opportunities to } \\
\text { practice Swedish }\end{array}$ \\
\hline $\begin{array}{l}\text { Cognitive } \\
\text { (affordances associated } \\
\text { with language } \\
\text { processing) }\end{array}$ & $\begin{array}{l}\text { Enabling } \\
\text { English is a permanent background presence that facilitates } \\
\text { decoding and language processing } \\
\text { English is a resource for generating language content when } \\
\text { difficulties are encountered in TL interaction } \\
\text { English provides a 'foundation' or 'model' upon which } \\
\text { conceptual understandings of Swedish grammar, syntax and } \\
\text { vocabulary can be constructed } \\
\text { Due to typological similarities, learning Swedish can facilitate } \\
\text { the retention/development of competence in English } \\
\text { Constraining }\end{array}$ \\
\hline
\end{tabular}


Language interference

The inability to control intrusions of English generates negative affect

Belief in a need to compartmentalize languages

Fear of L2 (English) attrition

Background presence of English provides a reminder of being in a communicatively disadvantaged situation

Perceptions of overreliance on English can generate language anxiety and negative introspection

\section{A social domain: affordances in everyday interactions}

Arriving in a new country migrants often find themselves in challenging situations. As Dewaele and Stavans (2012) explain, “they not only need to acquire a new language quickly but also need to navigate in an unfamiliar culture, in order to find a house, a job, health care, insurance and a driver's licence” (2). For migrants with English in their repertoires, arriving in an environment where English functions as a lingua franca, such challenges can be experienced as more manageable, especially initially:

When I came here, ahh, I only spoke English. And I knew, 'OK, I can communicate, I can do absolutely anything, anything at all'.*[Hanna]

It was very helpful. Sometimes if I say it to myself, if I don't know English I would be...like handicapped. It was very helpful. And...um... great that everybody here speaks, you can't say everybody, but mostly everybody speaks English. This is very good for me. /.../ When I first arrived to the airport and they wanted to take a taxi to [place] to my family. Um...everything. When I came here I didn't have clothes I told you that I went like... and I went to buy clothes from the shops everywhere the ladies there they speak English. That was helpful. At the Immigration, everywhere. [Safia] 
Even after early adjustment processes, English continues to function as an affordance facilitating social interaction:

English helps because almost all Swedish people know English, so when you are talking, talking, talking and then I don't know this word in Swedish you can say it in English and they will understand it and that's great [Elena]

For me it was very important to speak in English and I think that it is very fortunate that many Swedes can speak English. If you go to the shops or other places and you can't cope in Swedish, you can speak English and everyone will understand you.*[Galina]

English always helps me, I think. Because still now I can say if I don't feel myself to explain in Swedish, err, there are many places where they don't have the time to listen to our Swedish, like I'm not perfect, so it's better to direct talk in English...[Mumtaz]

In recurring interactions, such as conversations with Swedish-speaking neighbours, English has a facilitating function:

I switch to English words...so that I can express and participate in the conversation because I know, I understand, but I cannot express it thoroughly [Carmen]

I feel relaxed with her because she also knows how to speak English. So we talk like naturally. And...I have also a friend there in the community, but she only talks little English sometimes...when we talk we have dictionaries like that. But I'm trying to express myself also in Swedish. She can understand like that my Swedish may not be very good, but she understands my Swedish [Laura] 
However, while participants identify a range of perceived enablements associated with Swedish-speakers' communicative competence in English, it is an affordance that can also be constraining. As Hanna explains, reliance on English can extend the period before using Swedish in interaction with TL-speakers is established:

I think there are advantages and disadvantages. The advantages, that I could communicate. There were no problems with people, and I could ask for, I don't know, the key to the laundry room. Or I could ask in the population registration office. Or in school, with my daughter. The first visits to the school I asked, the first appointment I had with the doctor, I asked things in English, and it was really great. /.../ The advantages were that I could communicate. The disadvantages, I started, well, I started to use Swedish later, you could say, because I was scared that I couldn't say things so well in Swedish.*

As she goes on to explain, her hesitancy in using Swedish could be traced to greater confidence speaking English:

I couldn't speak for eight months. I said nothing in Swedish to people other than my friends, my, my school friends. I said nothing.

I: $\quad$ Why was that?

Because I was scared. And when my husband was unemployed and I needed to ask about something, ah, a man in the population registration office. I went to him and said to him: 'I can't speak in Swedish'. And then I started to speak. It was...I don't know why. I think that, ah, always it was, ah...the other language. That I could use and I could find good words.

I: $\quad$ Do you mean English?

Yes I mean English.* 
Because English provides a highly functional option in nearly all types of interaction, participants talk of having to force themselves to use Swedish:

When I go and buy something, I speak in Swedish, normally. When I went to the population registration office for...um...I also start in Swedish. I begin in Swedish and, but sometimes I am blocked. I...aha...continue in English. But first I start in Swedish. Because I must, I think. I must.*[Jasna]

Participants talk too about how they have to make concerted efforts to reduce the amount of English used in everyday transactions. Visam tells how he has consciously been reducing the amount of English he speaks:

I: $\quad$ OK. If its thirty percent now, if you go back several months, to when you came here, what was the percentage then?

V: $\quad$ Ninety percent.

I: $\quad$ Ninety percent, $\mathrm{OK}$.

V: $\quad$ Outside. Ninety percent, maybe more than ninety percent. But with time it decreases, ninety, seventy. And I, I have tried, tried to reduce English and force myself to speak Swedish.

I: $\quad$ So like today, when I say to you that we can take it in English, and you chose V: $\quad$ Swedish, yes. I force myself. I force myself to speak Swedish hmm...

I: $\quad$ Is it sometimes hard, to do that?

V: $\quad$ Yes, it is hard. Mostly in the beginning it was hard. It was hard. But I have tried and tried...*

Returning to Dewaele’s (2010) useful comparison of a linguistic affordance to a crutch, it would appear that, like patients in rehab whose goal is unaided mobility, participants go through a sometimes painful process of learning to stand on their own two feet without artificial support.

A material domain: affordances in digital medias 
As Aronin and Ó Laoire (2013) explain, societal shifts related to globalization have given rise to new sets of digitally-mediated materialities and technology-generated artefacts that form the material culture of multilingualism. The near ubiquity of English in different material forms is perceived by participants as offering affordances that are both enabling and constraining. That TV programs and films are broadcast with Swedish subtitles is identified as a particularly important affordance facilitating the acquisition of Swedish. Reading the subtitles while listening to English language dialogue is frequently mentioned:

When they show...um...English-speaking series they have this translation in Swedish. You know unconsciously you will hear and read. [Safia]

I start my Swedish, because I was very passionate to learn Swedish, so I start from TV. I opened the TV channels and I used to have English programs and they got translation under, because if I start from the Swedish so I could...maybe it was difficult...so I start from the English with the...um... Swedish translation. [Mumtaz]

However, while functioning as an enabling resource, there is also a risk that, when absorbed in the program, concentration drifts and focus on the subtitles can lapse:

When I watch TV and there is an English program, and I'm looking at the Swedish text, after five, maybe ten minutes, I don't look at the text. I just hear the English. And that's not good.*[Andras]

While many of the participants talk about the value of Swedish-subtitled English-language programs, Andras suggests that such an extensive English-language offering can also have negative consequences: 
Sometimes you listen to radio programs. One [public service channel]. Here are good Swedish programs. And sometimes there are good programs on SVT [public service TV channels] or others...OK, good, but I think that err Swedish programs are about $40 \%$. And $60 \%$ are English. And American. That is not good. You can’t integrate into society.*

The sense of a pervasive presence of English also extends to other digital arenas, participants talking frequently of how they use different English-language online resources, such as Google translate. Firman, for example, tells of how English-language digital dictionaries can be very useful:

Using my phone I can translate directly to English. Other languages too because here there is Internet. If it says, then I translate directly to Arabic. Or Kurdish, my mother tongue. And if there isn't any internet I translate direct to English.*

However, while online English-language media provide enabling affordances, there is also a sense that, like the subtitles, opportunities for learning Swedish may be lost, as Carmen explains:

It's high-tech for today, I can search and...like in I find in my mobile phone, it's not a problem, only I have to study more, read more in Swedish

Mumtaz, in the context of striving to improve her Swedish language skills, tells how the device on her laptop that automatically translates Swedish language Internet pages into English (her husband has installed the system) can be similarly constraining: 
In my laptop my husband has system he has translated, he has system that automatically translation in English. Is easy for him but no, I'm feeling from few months. When it comes my Swedish page gets translated into English by itself so it irritates me. Because I every day I learn Swedish and I try to, try to force myself to be, to learn or write Swedish so I'm feeling more comfortable with Swedish.

While it is evident in the interview data that digital tools that enable translations into and outof English have an important function in social interaction and learning Swedish, there is also a sense of the inescapability of English, and of a temptation to overly rely on this rather convenient crutch.

\section{A classroom domain: affordances associated with formal learning environments}

(i) A channel for classroom metacommunication

Talking about how English facilitates classroom learning, participants describe ways in which it enables effective metacommunication:

Friends to ask something to /.../ And we don't understand Swedish. I don't know how the people, he not understand Swedish or English, so how you understand the, the teacher, if you want to ask him about the grammar or...um...how a verb is going. It's difficult. But English is helping us to move...to face the first step of the language. [Babak]

When I can't find the right word, so then it's very good if you can ask in English.*[Galina]

When I couldn't say something in Swedish, I asked 'OK, what does it mean in English?' For example, I don't know, 'love’ for example. And when I asked I used English a lot. /.../ But, but if I were to compare with other people, like do a little competition, I know that they started to speak earlier, but now, now they don't have the same level as I have.*[Hanna] 
While Galina talks about the value of English in enabling her to ask teachers about vocabulary, Babak's response reveals how, because it creates a channel for dialogue about Swedish grammar and syntax conventions, he is able to develop a better understanding of rules governing Swedish. This, as Hanna explains, can provide long-term advantages. However it may also mean that the onset of TL communication is delayed.

(ii) A more functional lingua franca than Swedish

Not unlike the women in Norton's (2000) seminal study, outside of institutional contexts participants' encounters with TL-speakers are limited. The school environment emerges thus as an important arena for communication in Swedish; as Daria explains 'there is no other opportunity'. However, as Galina points out, 'Many of the participants here use English’*. Given the heterogeneity of learner groups, for some participants English can offer a more effective and communicatively rewarding lingua franca option than Swedish:

As I told you...we speak all the time English. Even, we don't have many...when we start we didn't have words to...express ourselves...that's why we...it's easy to speak in English [Daria]

In this sense lingua franca English is perceived as constraining opportunities for TL interaction. However, at the same time opportunities to use Swedish are, for many participants decidedly limited (see Henry in press). Consequently migrants need to be alert to the opportunities that the environment provides, as Daria explains:

We made a deal, we should just speak Swedish, even if it was horrible or any, or bad... 
The lack of authentic opportunities to interact with TL-speakers means too that, in the school environment, the pleasure and meaningfulness of social interaction is at times sacrificed in pursuit of the goal of TL-development.

\section{A cognitive domain: affordances associated with language processing}

As de Bot (1992) and Grosjean (1998, 2001) explain, in bilingual situations languages operate at different levels of activation, the language not in use in producing an utterance nevertheless activated in cognition. In addition to talking about code-switching and other languaging practices (see Henry in press) participants describe how, when communicating in Swedish, English is always there in the background. Safia, for example, says she is always thinking in English:

I: $\quad$ And when you are using Swedish, do you find that you're thinking in Swedish or are you thinking in Arabic or?...

S: $\quad$ I think in English. I think in English.

Viewing English in a similarly enabling way, Mumtaz tells how, when communicating in Swedish, she first thinks things through, not in her L1 (Urdu), but in English:

So I always think in English and I translate in Swedish. So that it makes ...um...perfect...um...sometimes not so perfect but often eighty percent helps, but if I think in my own language so...I can't, it doesn't work.

Functioning as a resource for generating language content when difficulties are encountered in TL interaction, English has a similarly enabling effect: 
Very often, when I ask, when you ask about something, or when I can't think of something, I say 'yes, you know that in English it means this and this and this'. And this happens very often.*[Hanna]

Daria tells how she draws on both French and English when looking for words in Swedish, but that searches of her store of English vocabulary usually come first:

D: $\quad$ Swedish language contain a lot of words also from French language, like 'window', um...but when I...like dominera [Eng=dominate]. I think first in English. If I didn't find it in English I search in French. That's what, what happens.

I: $\quad$ OK, and does, does that happen, if you say so, a lot of the time, most of the time, or not very often? That you're searching, looking for a word in English, looking for a word in French? How often do you find yourself doing that?

D: $\quad$ All the time.

In addition to the facilitation of ongoing language processing, participants talk about how English functions as a ‘foundation' or 'model' upon which conceptual understandings of Swedish grammar, syntax and vocabulary are constructed:

The foundation is English. Because I've got a friend. So English is the foundation, to be able to go to Swedish.*[Visam]

I still have to use English. As my model for grammar [Laura]

I make English as my foundation to learn the Swedish words, because there are some words that are related...and spelling and pronunciation [Carmen]

While participants all identify enabling affordances connected with English as a source of supply in TL communication and security in being able to switch languages when 
encountering problems, the triggering of English as a cognitive resource is not always intentional.

For some participants the unintended and unexpected intrusion of English into Swedish can be experienced as problematic. In the following sequence from an interview conducted in Swedish, Andras’s use of the English word ‘depth’ triggers a reflection as to how he sometimes feels unable to control his use of English:

A: $\quad$ I study Swedish in school. And I didn't study English in school. And, I don't know, those two languages, they have different dep in my brain.

I: $\quad$ You mean depth? Djup? [depth]

A: $\quad$ Yes, yes, yes, depth, yes.

I: $\quad$ It's fine if you want to use English sometimes...

A: $\quad$ Yes, yes. And now I thought I spoke Swedish, depth, but no, I spoke English...If for example there was a problem on the way here, I'd start speaking English. If there were situations, for example if I was to have an accident or something, so the first language I would use is English. And I don't know why.*

Elena, another participant who makes the observation that controlling the two languages isn't easy, uses the analogy of a 'button' of which she is not fully in control:

There's that button English/Swedish in your head. But it's not that easy. Because it's like a train. They speak Swedish, Swedish, Swedish, and then someone asks 'er, can you take a picture of me?' And you say, 'yes of course'. But you could say 'Yeah sure' instead. But no. You are 'sure' in Swedish now?*

For Safia, recently arrived in Sweden from war-torn Syria, awareness of cognitive processing in English provides a reminder of the communicatively disadvantaged situation she finds 
herself in, and a sense of how life might have been, or could be different in a setting where communication takes place in English:

I: When you, when you are in a situation, here or anywhere else, when you're speaking Swedish? What's going on inside your mind?

S: $\quad$ 'God I wish you, God I wish that you speak English'. That what I'm thinking. 'I wish that you speak English'. Or that I'm in England or America or Australia or...that's exactly what I feel. I wish Canada, for example. 'Why do you speak Swedish?'

There is an additional sense in which the background presence of English can function in a constraining manner. Permanently available as a communication option, perceptions of overreliance can generate language anxiety. Having often to compensate for deficiencies in Swedish, filling in gaps with English can, as Jasna explains, generate negative introspection:

I: $\quad$ Say you're talking to someone, like at the health centre or at an interview, or when you're talking here. And you can't find the Swedish words...

J: $\quad$ I put it in English. I do that.

I: $\quad$ How does that feel?

J: $\quad$ Shame. Sometimes. Shame. But I also think it's better than being silent. I can for example, I could be silent. Or say sorry and $O K$, then I'll take it in English.*

The negative emotions triggered by unintentional intrusions of English and the reluctant recourse to English when faced with lexical deficiencies Jasna describes can play a role in upholding the commonly-held view of a need to compartmentalize languages:

I have to concentrate on one. I can't mix languages*[Galina] 
I have to not think in English. I must. I must forget. *[Jasna]

And now I need to err forbid English. Because I feel that it is maybe a good method.*[Andras]

Another factor contributing to this view is teachers' advice, as Laura recounts:

They say that I have to forget my English in order to concentrate on Swedish. I tried it, but it's more that I don't understand Swedish without my English

The sense of a need to keep languages separate is echoed when, over a longer timescale, participants reflect on their repertoires, many giving voice to the notion that focusing on learning Swedish is, unavoidably, detrimental to the maintenance of English. Elena, for example, expresses a fear that focus on Swedish may have an attritional effect on her English:

I know that it is, it is like muscles. If they are not used you lose them.*

This insight, she explains, was triggered by a sobering experience:

I had a test, yesterday, in English, an oral test, and it was hard to /.../ to remember...words in English, that I wanted to say in Swedish. Usch. It was strange.*

Firman says that, over the preceding months, he has probably lost quite a bit of his English:

I maybe forgot English. In order to concentrate so much on Swedish. I must get it back. You, you can speak with me, but I can't answer. But I understand. After this, after Swedish, I shall start thinking about starting English.* 
Andras, whom we have seen places an embargo on using English, has similar thoughts:

And when I speak a little bit better Swedish. Then I can develop English again. Maybe.*

In talk about the need to preserve skills in English over a longer time perspective, two main reasons emerge. For participants with transnational family/social networks there is a desire to maintain skill levels for social reasons:

Before English was on a much higher level. And now when it is not so good, it doesn't work as well, and for example I can visit my friend who lives in England. And I am scared, since I, I can't ask any questions. *[Hanna]

I want to improve my English. In fact I'm not good in English. My family who lives in Australia, my husband's two brother and his wife and kids and I feel very embarrassment to speak. [Mumtaz]

For other participants though there is a sense that settling in Sweden might not be permanent. Prioritizing Swedish, at the perceived expense of English, thus appears as problematic:

I like English and I want to study English in the future. And. You know English, when you speak English you can err move to other countries all over the world.* [Andras]

See the language English is number one in the world, yes. I want to keep my English because if you're travelling outside the Swedish I don't think so that you will use the Swedish language. [Babak]

I don't know if I will continue here or I will come back to Syria and continue 
there. And that's really confuse me when, well, not confuse but sometimes I feel Swedish is language that I will not use. I will just use in Sweden, if I will not live in Sweden, I will...I'm wasting my time. [Daria]

If I would know that I'm staying here. I will plan for long time. But now I have only three years and I know that I'm going to learn Swedish, of course, to find a job or something, but the moment that I'm going to leave this country I will throw Swedish in the garbage. Because you can't use Swedish anywhere. Even. It's only here. [Safia]

Finally, although an 'either/or' perspective dominates participants’ views about language acquisition and maintenance, one participant expresses the view that, because of typological similarities, learning Swedish can actually help her retain her English:

But now I'm trying to learn myself Swedish so I think I'm going to, I'm going more better in English because the way we speak Urdu is not same. But English and Swedish are. I think they are similar in the sense when you ask and when you reply so I think you can I think is more...it's more, what can I say, in Urdu we have tenses, prepositions but we use in other way. But in European language and English I think they use in other way. So if you are good in English, very good in English, so you are good in...you can learn quickly other European languages. And if I'm good in Swedish, so I will keep English. [Mumtaz]

\section{Discussion}

Taking stock

Affordances provide a useful device that enables the mapping of ways in which, in an environment where it functions as a contact language in contact zone encounters (Canagarajah 2013), lingua franca English can both facilitate and constrain TL communication and acquisition. Outside of their immediate home environments the study participants (many of whom live in the types of super-diverse multilingual neighbourhoods described by Blommaert 
(2010)), find themselves almost permanently in situations where interlocutors are generally willing to speak English (Bolton and Meirkord 2013) and where language mixing is regarded as legitimate (see Henry, in press). Consequently English plays an important role in facilitating initial orientation in new social contexts and in enabling various types of social interaction. Participants also find themselves in material environments where English is everpresent, not only as a medium conveying information, but also as a resource for learning. Because of the typological proximity between Swedish and English, and distance between Swedish and the participants’ Slavic, Uralic, Afroasiatic, Indo-Ayrian, and Austronesian L1s, English facilitates the acquisition of Swedish. A consequence of metalinguistic awareness and processes of CLI, participants describe English as functioning as a "foundation" or "model" for learning Swedish. Furthermore, in the classroom English provides a channel for metacommunication, enabling participants to develop understandings of Swedish grammar and syntax.

At the same time the data reveals that affordances associated with English can also have constraining effects. As we have seen, perceptions of an uncontrolled osmosis of English into Swedish in TL processing can generate negative affect. Similar perceptions are also found in material domains. Moreover, when communicative challenges necessitate a shift in the selected language from Swedish into English, negative self-knowledge can be triggered. For one participant, speaking Swedish is accompanied by a sense of frustration in not being/feeling able to communicate solely in English, and despondency associated with a longing to be in a wholly English-language environment. Participants also experience a need to keep languages separate and express a fear that, in developing skills in Swedish, competence in English - something that is highly valued - runs the risk of erosion. 
Although the factors contributing to patterns of language use are numerous and complexly interrelated (see Henry in press), it appears that English has a longer-term constraining effect, delaying the process of beginning to speak Swedish. As Ożańska-Ponikwia and Dewaele (2012) suggest, frequency of TL use and language self-confidence increase in relation to the length of time spent in a host country. Further, the same authors make the point that, as a consequence of processes of reciprocal causation, increased use and confidence in the TL means that migrants become more extravert, open-minded, agreeable and empathic, meaning that they more quickly build up networks of L2 interlocutors. In the current study there are indications that, as a consequence of reliance on English, the point in time when migrants begin speaking Swedish can be delayed. In that English often offers a more effective communicative medium, confidence and willingness to use Swedish can be negatively impacted. Reliance on English can also have the effect of delaying processes of developing an openness to the new environment, the seeking-out of interaction with TL-speakers, and the development of a curiosity and interest in the TL and TL culture. Not only does this contribute negatively to the frequency with which Swedish is used in communication, but it can also have a negative longer-term influence on L2 socialisation processes (cf. OżańskaPonikwia and Dewaele 2012).

\section{Sometimes enabling, sometimes constraining: in-the-moment cognitive processing}

As we have seen, within each identified domain affordances associated with English differ. While in some situations English is perceived as offering possibilities, in others it is associated with constraints. Here it is important to recall that the individual's attunement to an affordance does not take place in a decontextualized or an objective manner. Rather, an affordance becomes such because of the individual's ability, in the moment, to recognize and react to a particular feature of the environment (Greeno 1998). Consequently, the ways in 
which an affordance is perceived will differ not only in relation to the individual's personality, but also as a consequence of their motivational and affective state at the particular point in time when the affordance is perceived. In combination with trait personality characteristics (see Dewaele 2012), the dynamic interactions of factors such as anxiety, motivation, perceptions of competence and willingness to communicate (MacIntyre and Leggato 2014; Macintyre and Serroul 2015) will impact on the ways in which English is attuned to. As Dörnyei and Tseng (2009) explain, because the challenge of TL communication creates an emotional state very different to the normal L1 communication mode, this “may modify one’s perceptions of the latent sociolinguistic features/constraints of the interaction” (121). In situations where confidence is high, where the individual has a positive self-conception as a TL-speaker, where there is motivation and a desire and willingness to engage in TL-interaction or with TL-learning activities, the opportunities and possibilities that English offers - its enabling properties - may be those that are generally attuned to. However, if confidence is low, if the individual has a negative self-image as a TLspeaker and experiences the lack of a general desire or willingness to engage in TL interaction and activities and, in particular, if anxiety is experienced, the individual may find him/herself more attuned to the constraints that the same affordance imposes on successful learning/interaction.

In his language mode theory, Grosjean $(1998,2001)$ explains how, when interaction takes place, a bilingual's languages are cognitively active to varying degrees. A continuum exists where, at one end, the individual can be in a complete monolingual mode. At the other end, when interacting with bilinguals sharing two or more languages and in contexts where language mixing might take place, they can be in complete bilingual mode, recent neurolinguistic research demonstrating that a language remains active and easily accessible 
when the other is used (Hoshino and Thierry 2011). As the current analyses reveal, participants frequently find themselves in spaces close to the 'bilingual mode' endpoint of this continuum. Not only is English encountered in various social/societal contexts and a frequently-used communicative option, when Swedish is the "selected language” (de Bot 1992), English functions as a supplier of input, playing an active role in TL-processing and production.

When different languages are simultaneously active in cognition, this has effects on the learner's self-concept. Specifically, when multilinguals draw on Lx resources in support of Ly communication, the Lx self-concept becomes cognitively active (Henry 2011). As the current inventory of affordances reveals, English is frequently present in TL-communication and processing, meaning that participants are almost invariably in 'bilingual' mode' (Grosjean 2001). This means that the English-speaking/using self-concept will be frequently constituent in working cognition (in-the-moment cognitive processing). Within the 'working selfconcept' processes of self-concept comparison take place (Henry 2015; Markus and Kunda 1986; Markus and Nurius 1986). Having first to think things through in English before communicating, searching for English vocabulary to support communication, switching to English when communication difficulties arise, or being reminded of English when it is encountered in various digital media, can all constitute situations that are likely to trigger selfconcept comparisons. In such comparisons weaker language-speaking/using self-concepts (for the current participants often the self-concept as a Swedish speaker/user) can be contrasted negatively with stronger language-speaking/using self-concepts (e.g. as an English speaker/user). These types of $\mathrm{L} x$-Ly comparisons can generate negative introspection and excessive self-monitoring that take up space in working memory, leading to reduced 
information-processing abilities and a reduced willingness to use the TL (MacIntyre, 2007; MacIntyre and Gardner 1991; MacIntyre and Legatto 2011).

Because of the frequency with which they are in 'bilingual mode' - English providing a viable communicative option in social domains, having important metacommunicative and social functions in classroom domains, a frequent constituent in material domains and impacting on language processing in cognitive domains - the individual has to learn to deal with these constant cognitive and emotional demands. The success with which negative thoughts can be rebuffed and, through the recruitment of positive self-knowledge into the working self-concept, negative Lx and Ly self-concept comparisons offset, depends on current mood and emotional states as well as trait level personality characteristics. The ways in which negative self-concept comparisons are counteracted in-the-moment, as well as the more enduring response patterns that emerge over time, have implications for how affordances are perceived. An individual who is able to offset negative self-concept comparisons through the recruitment of positive self-knowledge may more generally attune to the enabling properties of English. However, for those individuals who are less successful, dwelling overly on perceived communicative deficiencies in the TL, a pattern of attuning towards its constraining properties may emerge.

\section{Conclusion}

As Aronin and Singleton (2012, 312) make clear, the concept of affordances “deserves more active and systematic use on the part of multilingualism researchers, since affordances can genuinely shed new light on multilingual phenomena, in particular, on second and multiple language acquisition” (see also Aronin 2014). In the inventory created here affordances associated with English that both enable and constrain the acquisition of Swedish were 
identified in four domains. While the aim has been to cast light on a particular phenomenon of contemporary multilingualism - the impact of lingua franca English on different aspects of third language acquisition - the inventory created here forms only a modest beginning to work in this area. Nevertheless, insights of practical value arise. In particular findings underscore the importance of calls recently made by a number of researchers (e.g. DeAngelis 2011; Otwinowska-Kasztelanic 2014) for the need for language teachers to be made aware of the benefits of multilingualism, that speaking other languages can facilitate the acquisition of TLs, and of the fallacy that languages need to be kept apart in the mind of the learner in order to avoid interference.

For teachers in Sweden and other countries where, for many migrants, English functions as a contact language in contact zone encounters (Canagarajah 2013), there is a need to develop awareness of the consequences of practices that favour the sole use of the TL in developing communicative competence (Rosén and Bagga-Gupta, in press). Rather, teachers should be encouraged to position lingua franca English as a mediation tool (Otwinowska-Kasztelanic 2014) that can bridge gaps between languages and draw learners' attention to lexical and syntactical similarities. In developing a pedagogy of third language learning where lingua franca English is used in a mediational capacity, teachers need in particular to draw learners' attentions to the enabling affordances associated with English. They need to help them recognize that language mixing is a natural (and beneficial) consequence of being multilingual, and to explain that comparisons of language-speaking/using self-concepts are normal and can be compensated for by the generation of empowering visions of a multilingual self (for a discussion see Henry, 2014). Most importantly, they need to help learners develop an awareness that languages do not need to be kept separate, that L2 attrition is not a necessary consequence of TL-acquisition, and, on the contrary, that the acquisition of an 
additional language can be enriching for the learner's other languages. Simply put, they need to encourage a mindset in which, as voiced by the participant in the final extract in the abovecited data, learning one language is seen as advantageous for the other(s).

\section{A final caveat and directions for future research}

In addition to the normal cautions required when extrapolating from findings derived in a particular context and from a limited number of individuals, there is an important caveat that needs to be made in relation to the research carried out. Because the purpose has been to produce an inventory of affordances associated with English and, drawing on this inventory, to consider the implications for the acquisition of Swedish, regard has not been paid to the role that might be played by the individual's other languages. Specifically, because the participants in the study are all multilingual it is possible that, rather than being in 'bilingual mode' (Grosjean 1998, 2001), they are in fact operating in 'multilingual mode' (Dewaele 2001). As Dewaele (2001) suggests, speakers of more than two languages may function in a multilingual mode where all of their languages are concurrently active, none ever completely switched off. If the learners here are operating in multilingual mode, all of their languages (not only English) are likely to contribute in language processing. Thus it is conceivable that dominant constellations of languages (Aronin 2006, Aronin and Singleton 2012) are implicated in facilitating/hindering processing in Swedish. Indeed, for speakers of other European languages (five of the current participants are speakers of French and two of German) it is perhaps not just the similarity of English to Swedish, but also various crosslinguistic factors that push some participants, but not others, to draw on English more extensively. Thus, in addition to research from different settings more closely examining migrants' uses of English as a resource in learning different European TLs, research that takes account of the full range of the individual's language repertoires in facilitating/hindering TL acquisition and processing would be of great interest. In such work a closer examination of 
the impact of cognitive/affective processes on language processing would be of particular value.

\section{Acknowledgments}

I would like to thank the anonymous reviewers of this paper for the many important insights they have offered.

\section{References}

Akrich, M. and Latour, B. 1992. A summary of a convenient vocabulary for the semiotics of human and nonhuman assemblies. In W. Bijker and J. Law (eds) Shaping technology/building society. Cambridge, MA: MIT Press.

Aronin, L. 2006. Dominant language constellations: An approach to multilingualism studies. In M. Ó Laoire (ed.) Multilingualism in educational settings. Hohengehren: Schneider Publications.

Aronin, L. 2014. The concept of affordances in applied linguistics and multilingualism. In M. Pawlak and L. Aronin (eds) Essential topics in applied linguistics and multilingualism. (pp. 157-174). Switzerland: Springer.

Aronin, L. and Ó Laoire, M. 2013. The material culture of multilingualism: moving beyond the linguistic landscape. International Journal of Multilingualism 6, 17-36.

Aronin, L. and Singleton, D. 2010. Affordances and the diversity of multilingualism. International Journal of the Sociology of Language 125, 105-129.

Aronin, L. and Singleton, D. 2012. 'Affordances Theory’ in multilingualism. Studies in Second language Learning and Teaching 3, 311-331.

Blommaert, J. 2010. The sociolinguistics of globalization. Cambridge: Cambridge University Press. 
Bolton, K. and Meirkord, C. 2013. English in contemporary Sweden: Perceptions, policies, and narrated practices. Journal of Sociolinguistics 17, 93-117.

Braun, V. and Clarke, V. 2006. Using thematic analysis in psychology. Qualitative Research in Psychology, 3, 77-101

Cabau, B. 2009. The irresistible rise and hegemony of a linguistic fortress: English teaching in Sweden. International Multilingual Research Journal 3, 134-152.

Canagarajah, S. 2013. Translingual practice: Global Englishes and cosmopolitan relations. Abingdon: Routledge.

Cenoz, J. 2003. The additive effect of bilingualism in third language acquisition: A review. International Journal of Bilingualism 7, 71-87.

Clyne, M. and Sharifian, F. 2008. English as an international language: Challenges and possibilities. Australian Review of Applied Linguistics, 31, 28.1-28.16.

Cook, V. 2009. Language user groups and language teaching. In V. Cook and W. Li (eds.), Contemporary Applied Linguistics Volume 1: Language Teaching and Learning. London: Continuum.

Cook, V. 2013. ELF: Central or atypical second language acquisition? In D. Singleton, J. A. Fishman, L. Aronin and M. Ó Laoire (eds.). Current multilingualism: A new linguistic dispensation. Berlin: De Gruyter.

De Angelis, G. 2011. Teachers’ beliefs about the role of prior language knowledge in learning and how these influence teaching practices. International Journal of Multilingualism, 8, 216-234.

De Angelis, G. and Dewaele, J-M. 2011. New trends in crosslinguistic influence and multilingualism research. Bristol: Multilingual Matters. 
De Bot, K. 1992. A bilingual production model: Levelt’s speaking model adapted. Applied Linguistics 13, 1-24.

Dewaele, J.-M. 2001. Activation or inhibition? The interaction of L1, L2 and L3 on the language mode continuum. In J. Cenoz, B. Hufeisen and U. Jessner (eds). Cross-linguistic influence in third language acquisition: psycholinguistic perspectives. (pp. 69-89). Clevedon: Multilingual Matters.

Dewaele, J.-M. 2010. Multilingualism and affordances: Variation in self-perceived communicative competence and communicative anxiety in French L1, L2, L3 and L4. International Review of Applied Linguistics 48, 105-129.

Dewaele, J.-M. 2012. Personality: Personality traits as independent and dependent variables. In S. Mercer, S. Ryan and M. Williams (eds). Psychology for language learning: Insights from research, theory and practice. (pp. 42-57). Houndmills: Palgrave Macmillan.

Dewaele, J.-M. and Stavans, A. 2013. The effect of immigration, acculturation and multicompetence on personality profiles of Israeli multilinguals. International Journal of Bilingualism 18, 203-221.

European Commission 2012a. Special Eurobaromoter 386: Europeans and their languages. Brussels: European Commission.

European Commission 2012b. SurveyLang: The European Survey on Language Competencies. Brussels: European Commission.

Gibson, J.J. 1979. The ecological approach to visual perception. Hillsdale: Lawrence Erlbaum.

Greeno, J.G. 1998. The situativity of knowing, learning, and research. American Psychologist 53, 5-26. 
Grosjean, F. 1998. Studying bilinguals: Methodological and conceptual issues. Bilingualism: Language and Cognition 1, 131-149.

Grosjean, F. 2001. The bilingual's language modes. In J. Nicol (ed.). One mind two languages: Bilingual language processing. (pp.1-22). Oxford: Blackwell.

Henry, A. 2011. Examining the impact of L2 English on L3 selves: A case study International Journal of Multilingualism 8, 235-255.

Henry, A. 2014. The motivational effects of crosslinguistic awareness: developing third language pedagogies to address the negative impact of the L2 on the L3 self-concept. Innovation in Language Learning and Teaching 8, 1-19.

Henry, A. 2015. The dynamics of possible selves. In Z. Dörnyei, P.D. MacIntrye and A. Henry (eds). Motivational dynamics in language learning. (pp. 83-94). Bristol: Multilingual Matters.

Henry, A. in press. Swedish or English? Migrants' experiences of the exchangeability of language resources. International Journal of Bilingual Education and Bilingualism. Doi:Xxxxxxxxxxxxxxxxxxxxxx

Henry, A. and Goddard, A. in press. Bicultural or hybrid? The second language identities of students on an English-mediated university program in Sweden. Journal of Language, Identity, and Education.

Hoshino, N. and Thierry, G. 2011. Language selection in bilingual word production: Electrophysiological evidence for cross-language competition. Brain Research, 1371, 100109.

Hultgren, K., Gregersen, F. and Thogersen, J. 2014. English at Nordic universities: Ideologies and practices. In K. Hultgren, F. Gregersen, and J. Thogersen (eds). English in Nordic universities: Ideologies and practices. (pp. 1- 26). Amsterdam: John Benjamins. 
Hutchby, I. 2002. Technologies, texts and affordances. Sociology 35, 441-456.

Jessner, U. 2008. Teaching third languages: Findings, trends and challenges. Language Teaching 41, 15-56.

Norman, D.A. 1999. Affordances, conventions and design. Interactions 6, 38-43.

MacIntyre, P.D. and Gardner, R.C. 1991. Methods and results in the study of anxiety in language learning: A review of the literature. Language Learning 41, 85-117.

MacIntyre, P.D. 2007. Willingness to communicate in the second language: Understanding the decision to speak as a volitional process. Modern Language Journal 91, 564-576.

MacIntyre, P.D. and Legatto, J. 2011. A dynamic system approach to willingness to communicate: Developing an idiodynamic method to capture rapidly changing affect. Applied Linguistics 32, 149-171.

Macintyre, P.D. and Serroul, A. 2015. Motivation on a per-second timescale: Examining approach-avoid motivation during L2 task performance. In Z. Dörnyei, P.D. MacIntrye and A. Henry (eds). Motivational dynamics in language learning. Bristol: Multilingual Matters.

Markus, H.R. and Kunda, Z. 1986. Stability and malleability of the self-concept. Journal of Personality and Social Psychology 51, 858-866.

Markus, H.R. and Nurius, P. 1986. Possible Selves. American Psychologist 41, 954-969.

McKay, S. 2002. Teaching English as an international language. Oxford: Oxford University Press.

Norton, B. 2000. Identity and language learning: Gender, ethnicity and educational change. Harlow: Pearson Education.

OECD. 2013. International Migration Outlook.

Otwinowska-Kasztelanic, A. 2009. Language awareness in using cognate vocabulary: The case of Polish advanced students of English in the light of the theory of affordances. In J. 
Arabski and A. Wojtaszek (eds), Neurolinguistic and psycholinguistic perspectives on SLA (pp. 175-190). Bristol: Multilingual Matters.

Otwinowska-Kasztelanic, A. 2011. Awareness and affordances: Multilinguals versus bilinguals and their perceptions of cognates. In G. De Angelis and J.-M. Dewaele (eds), New trends in crosslinguistic influence and multilingualism research (pp. 1-18). Bristol: Multilingual Matters.

Otwinowska-Kasztelanic, A. 2014. Does multilingualism influence plurilingual awareness of Polish teachers of English? International Journal of Multilingualism 11, 97-119.

Ożańska-Ponikwia, K. and Dewaele, J.-M. 2012. Personality and L2 use: The advantage of being openminded and self-confident in an immigration context. In L. Roberts, C. Lindqvist, C. Bardel and N. Abrahamsson (eds), EUROSLA Yearbook. Amsterdam: John Benjamins.

Ringbom, H. 1986. Crosslinguistic influence and the foreign language learning process. In E. Kellerman and M. Sharwood Smith (eds), Crosslinguistic Influence in Second Language Acquisition (pp. 150-62). New York: Pergamon.

Ringbom, H. 1987. The role of the first language in foreign language learning. Clevedon: Multilingual Matters.

Rosén, J. and Bagga-Gupta, S. (in press). Prata svenska, vi är i Sverige! [Talk Swedish, we are in Sweden!] A study of practiced language policy in adult language learning. Linguistics and Education.

Segalowitz, N. 2001. On the evolving connections between psychology and linguistics. Annual Review of Applied Linguistics 21, 3-22.

Shotter, J. and Newson, J. 1982. An ecological approach to cognitive development: implicate orders, joint action, and intentionality. In C. Butterworth and P. Light (eds). Social cognition: Studies in the development of understanding. Harvester, Sussex. 
Singleton, D. 2006. Lexical transfer: Interlexical or intralexical? In J. Arabski (ed.) Crosslinguistic influences in the second language lexicon. (pp. 130-143). Clevedon: Multilingual Matters.

Singleton, D. and Aronin, L. 2007. Multiple language learning in the light of the theory of affordances. Innovation in Language Teaching and Learning 1, 83-96.

Swedish Media Council. 2013. Ungar och mediar 2012/2013: Fakta om barns och ungas användning och upplevelser av medier (Young people and the media 2012/2013: Facts on children and young people’s media use and experiences). Stockholm: Statens Media Råd.

Van Lier, L. 2000. From input to affordance: Social-interactive learning from an ecological perspective. In J. Lantolf (ed.). Sociocultural theory and second language learning. (pp. 245-259). Oxford: OUP.

Vertovec, S. 2007. Super-diversity and its implications. Ethnic and Racial Studies 30, 10241054.

World Economic Forum. 2012. Global Information Technology Report.

\footnotetext{
i Gauged as around or above the midpoint on a line ranging from 'only basic phrases' to 'like a native speaker'

ii Three participants (Babak, Galina and Safia) were interviewed once due to leaving the program and illness.

iii Where two interviews were conducted the transcripts were treated as a single text.
} 